\title{
Pathophysiology, Management, and Outcomes of Fetal Hemodynamic Instability During Prenatal Cardiac Intervention
}

\author{
ARIELLE MIZRAHI-ARNAUD, WAYNE TWORETZKY, LINDA A. BULICH, LOUISE E. WILKINS-HAUG, \\ AUDREY C. MARSHALL, CAROL B. BENSON, JAMES E. LOCK, AND DOFF B. MCELHINNEY
}

\begin{abstract}
Departments of Anesthesiology, Perioperative and Pain Medicine [A.M.-A., L.A.B.], Departments of Cardiology and Pediatrics [W.T., A.C.M., J.E.L., D.B.M.], Children's Hospital Boston, Harvard Medical School, Boston, Massachusetts 02115; Department of Obstetrics \& Gynecology [L.E.W.-H.], Department of Radiology [C.B.B.] Brigham \& Women's Hospital and Harvard Medical School, Boston,
\end{abstract} Massachusetts 02115

\begin{abstract}
Prenatal cardiac intervention (PCI) may favorably alter the in utero course of some congenital heart defects. In our preliminary experience with PCI, fetal hemodynamic instability (FHI) characterized by bradycardia and ventricular dysfunction was common. This study evaluated the pathophysiology, management, and short-term outcomes of FHI during PCI for aortic stenosis with evolving hypoplastic left heart syndrome (HLHS), HLHS with restrictive atrial septum, pulmonary atresia with intact ventricular septum, and hydrops due to structural heart disease. From 2000 to 2006, 83 fetuses underwent PCI, with ventricular access in 63, atrial access in 17, and both in three. FHI occurred in 37 fetuses $(45 \%)$. FHI was associated with transventricular PCI (all but one case of FHI; $p<0.001)$ and large hemopericardium $(n=9 ; p=0.07)$. Prolonged FHI was associated with severe ventricular distortion during ventricular puncture $(p=0.06)$. FHI was treated with resuscitation medications in 31 of 37 fetuses and resolved in all 37. Five fetuses died within $1 \mathrm{~d}$ of PCI: four had FHI and one had a massive hemopericardium. FHI is common and clinically important during transventricular PCI and may be caused by a ventricular reflex or reduced cardiac output from cardiac distortion during ventricular puncture. Hemopericardium may be causative in a subset of fetuses.
\end{abstract}

(Pediatr Res 62: 325-330, 2007)

$\mathrm{I}^{\mathrm{n}}$ n some forms of congenital heart disease, relatively simple obstructive anomalies causing physiologic changes in utero may lead to more serious abnormalities of cardiovascular growth and development. For example, severe left ventricular (LV) outflow obstruction in the early fetus may produce myocardial and hemodynamic abnormalities resulting in growth arrest of the entire left heart complex, culminating in HLHS. Similarly, in fetuses with established HLHS, closure of the foramen ovale may cause left atrial hypertension, with subsequent abnormalities of lung parenchymal and vascular development that contribute to high mortality after birth $(1,2)$. Although such processes have not been well defined, the hypothesis that flow disturbances early in gestation can lead to abnormal cardiac growth is supported by experimental animal data (3-5) and by documented progression of isolated LV or

Received March 28, 2007; accepted April 19, 2007.

Correspondence: Doff B. McElhinney, M.D., Department of Cardiology, Children's Hospital, 300 Longwood Avenue, Boston, MA 02115; e-mail: doff.mcelhinney@cardio. chboston.org right ventricular (RV) outflow obstruction to ventricular hypoplasia in human fetuses $(6,7)$.

In fetuses with such congenital heart defects, PCI may limit the secondary abnormalities of growth or development that result from primary structural anomalies by restoring more normal hemodynamic conditions. Since 2000, we have offered PCI for selected fetuses with (1) severe aortic stenosis (AS) with evolving HLHS, (2) critically restrictive or intact atrial septum and established HLHS, (3) pulmonary atresia with evolving hypoplastic right heart syndrome (HRHS), and (4) hydrops fetalis due to structural heart disease (8-10).

Almost immediately, we observed that FHI characterized by bradycardia and ventricular dysfunction was common during PCI. Although cases of fetal cardiac arrest or bradycardia during other forms of fetal intervention have been reported (11-13), there is no clinical or experimental paradigm for FHI during PCI. Based on our preliminary experience, we hypothesized that PCI-induced FHI is mediated by either a direct cardiac reflex or an autonomic response to fetal hypoxia. We also proposed that maternal, anesthetic, and underlying fetal circulatory factors may contribute to FHI but are rarely causative. This retrospective study was performed to explore those hypotheses.

\section{METHODS}

Patients and PCI. All fetuses that underwent PCI between March 2000 (the first case performed) and November 2006 were included. PCI was attempted for (1) severe AS with evolving HLHS, (2) critically restrictive or intact atrial septum with established HLHS, (3) pulmonary atresia with evolving HRHS, or (4) hydrops fetalis due to structural heart disease. PCI procedures included aortic valvuloplasty, atrial septoplasty, and pulmonary valvuloplasty.

The technical details of fetal aortic valvuloplasty and atrial septoplasty were described previously $(8-10,14)$. The technique is similar for pulmonary valvuloplasty. The mother was positioned with left uterine displacement. General endotracheal anesthesia was induced with rapid sequence techniques and maintained with desflurane in $100 \%$ oxygen, supplemental narcotics, and muscle relaxant. Ephedrine and/or Neo-Synephrine (phenylephrine) infusions were titrated to maintain maternal mean blood pressure within $20 \%$ of awake baseline levels, as necessary. The fetus was given an intramuscular injection of atropine, vecuronium, or pancuronium and fentanyl.

Abbreviations: AS, aortic stenosis; FHI, fetal hemodynamic instability; HLHS, hypoplastic left heart syndrome; HRHS, hypoplastic right heart syndrome; LV, left ventricle (ventricular); PCI, prenatal cardiac intervention; $\mathbf{R V}$, right ventricle (ventricular) 
Ultrasound guidance facilitated direct access to the fetal heart with a 19- or 18-gauge cannula that allowed introduction of a guidewire and angioplasty balloon. The chamber(s) entered varied depending on the intended intervention: LV access for aortic valvuloplasty, RV access for pulmonary valvuloplasty, and atrial access for atrial septoplasty. Procedures in which a dilating balloon was inflated across the intended target with subsequent unambiguous improvement in color Doppler flow were considered technically successful.

A review of ultrasound recordings permitted quantification of important procedural times and evaluation of technical variables that were assessed to determine the extent of fetal cardiac manipulation: number of uterine and cardiac punctures, number of balloon inflations, duration of time with the cannula in the heart, extent of cannula manipulation after cardiac puncture, attempts at cardiac access with uncertain cannula/wire position, difficult imaging, ease of wire passage across the dilation target, and, when applicable, axis of ventricular access (Fig. 1) and severity of ventricular compression during puncture (Fig. 2). In general, the technical demands of the procedure precluded measurement of fetal umbilical or cerebral vascular flow patterns, or other hemodynamic variables, preceding or following FHI. Similarly, we could not assess the severity of access-related compression of the inferior vena cava or right atrium as an indication of compromised cardiac filling or the extent of cardiac torsion during manipulation of the access cannula.

FHI. We defined FHI as a fetal heart rate $\leq 110 \mathrm{~min}^{-1}$ for $\geq 30 \mathrm{~s}$ with concomitant dysfunction of the dominant ventricle (i.e. the RV in fetuses with AS or HLHS and the LV in fetuses with pulmonary atresia), and subclassified FHI according to severity: minor FHI (no resuscitation) or major FHI (resuscitation performed). Among patients with major FHI, we subclassified those in whom bradycardia and ventricular dysfunction lasted $\geq 10 \mathrm{~min}$, with a heart rate $<100 \mathrm{~min}^{-1}$, as having severe FHI.

Fetal resuscitation. Fetal resuscitation was typically initiated when fetal bradycardia exceeded 60 s. Resuscitation maneuvers varied, but usually included administration of intramuscular and/or intracardiac epinephrine medications directly to the fetus. Although practice varied, the initial dose was usually $1 \mu \mathrm{g} / \mathrm{kg}$ (fetal weight was estimated by biometry before PCI),
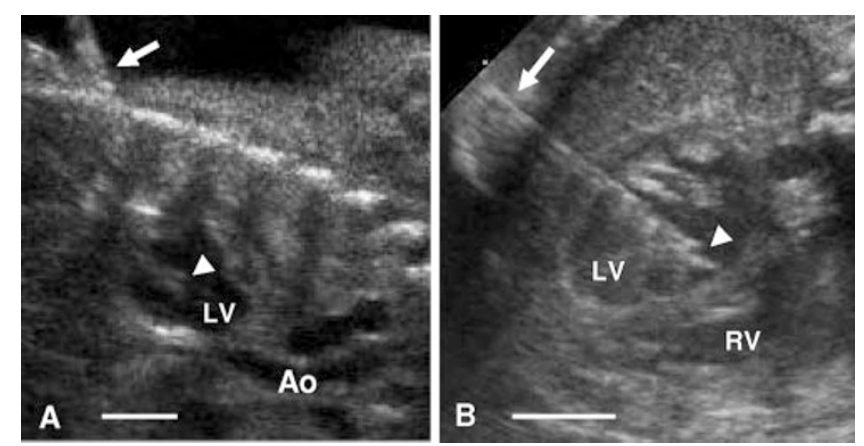

Figure 1. Echocardiograms during LV access in two fetuses undergoing fetal aortic valvuloplasty. (A) The cannula passes through the fetal chest, LV apex, and along the axis of LV outflow and ascending aorta (Ao). (B) The LV is entered through the posterolateral wall apical to the papillary muscle. The cannula is almost perpendicular to the interventricular septum and LV outflow tract. Arrows indicate the shaft of the cannula at the fetal chest; arrowheads indicate the tip of the cannula within the LV. Scale bars indicate $1 \mathrm{~cm}$.
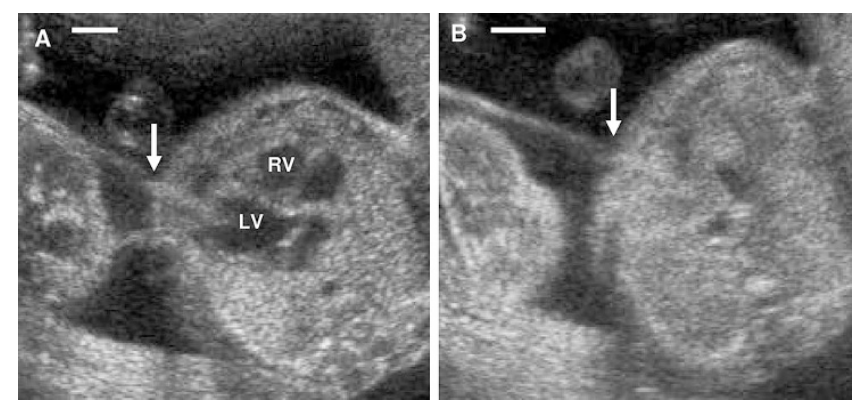

Figure 2. Echocardiograms in a fetus undergoing aortic valvuloplasty. The cannula is introduced at the apex, along the axis of LV outflow, and in $(A)$ is beginning to tent the LV myocardium inward. $(B)$ During LV puncture, the LV wall is inverted inward, with almost complete obliteration of the LV cavity. Scale bars indicate $1 \mathrm{~cm}$. with subsequent doses of 1 or $10 \mu \mathrm{g} / \mathrm{kg}$. Less often, intracardiac atropine $(0.1$ $\mathrm{mg}$ ) was given. In six recent cases, we infused epinephrine through the cannula used to introduce the dilating balloon, but in most cases, separate intramuscular or intracardiac access was obtained with a 22-gauge needle under ultrasound guidance. Delivery of the medication was confirmed with an echogenic blush.

Procedural complications. Procedural complications potentially contributing to FHI were assessed, including arrhythmia and hemopericardium, which were listed as a complications only if not present before PCI. Hemopericardium size was graded as small $(<3 \mathrm{~mm})$ or large $(\geq 3 \mathrm{~mm})$.

Data analysis. The primary outcome assessed was major FHI. Additional outcomes included any (major or minor) FHI, severe FHI, post-PCI fetal demise, and large hemopericardium. Outcomes were analyzed for the entire cohort, for patients in whom ventricular access had been attempted, and for patients who underwent attempted aortic valvuloplasty. Independent variables included fetal gestational age, type of cardiac access, procedure attempted, procedural times, maternal anesthetic and hemodynamic factors, transplacental access, laparotomy, and the procedural variables summarized in the first section of "Methods." In patients who underwent attempted aortic valvuloplasty, LV size was also analyzed. Analysis of variables associated with outcomes was performed using $\chi^{2}$ analysis or Fisher's exact text (for categorical variables) or independent-samples $t$ test or the Wilcoxon rank sum test (for continuous variables). Multivariable analysis of factors associated with outcomes was performed using logistic regression. Odds ratios (ORs) are presented with $95 \%$ confidence intervals (CIs). Data are presented as median (range) or frequency (percentage).

This study was performed in accordance with protocols approved by the Children's Hospital Committee on Clinical Investigation and the Brigham \& Women's Hospital Institutional Review Board.

\section{RESULTS}

Patients and PCI. During the study period, 83 fetuses underwent attempted PCI for severe AS with evolving HLHS $(n=50)$, critically restrictive atrial septum $(n=17)$, pulmonary atresia with evolving HRHS $(n=8)$, or hydrops fetalis due to structural heart disease $(n=8$, all with AS, an intact or restrictive atrial septum, and significant mitral regurgitation). Attempted procedures included aortic valvuloplasty in 58 fetuses, atrial septoplasty in 20, and pulmonary valvuloplasty in eight, with two separate interventions during the same procedure in three. Attempted intracardiac access was transventricular only in 64 cases, transatrial only in 17, and both in two. PCI was technically successful in 66 patients (80\%). The median duration between the first uterine puncture with the PCI cannula and removal of all PCI equipment from the fetus was $20 \mathrm{~min}$ (range, 4-165 $\mathrm{min}$ ). The median duration of maternal anesthesia was $90 \mathrm{~min}(34-240 \mathrm{~min})$.

FHI. Major $(n=31)$ or minor $(n=6)$ FHI occurred in 37 fetuses (45\%), with two separate episodes of major FHI in six. Thus, a total of 43 episodes of FHI occurred, 37 major and six minor. Eleven fetuses had severe FHI, with bradycardia and ventricular dysfunction lasting $\geq 10 \mathrm{~min}$ and a heart rate $<100$ $\min ^{-1}$. All fetuses with major FHI and six of seven with minor FHI underwent PCI with attempted LV $(n=30)$ or RV $(n=$ 6) access. Ventricular access was the only independent risk factor for FHI [OR $=9.3$ (95\% CI: 1.4-63), $p<0.001]$.

The points at which FHI occurred during PCI are summarized in Table 1 . The onset of bradycardia was a median of 26 min (12-104 min) after fetal anesthesia and 5 min (1.2-45 $\min$ ) after the initial ventricular puncture.

Because all cases of major FHI occurred during transventricular PCI, factors associated with FHI were analyzed for fetuses in which transventricular PCI was attempted. Data on these 66 fetuses are summarized in Table 2. Fetuses that 
Table 1. Timing of FHI

\begin{tabular}{|c|c|c|c|}
\hline & $\begin{array}{l}\text { All episodes of } \\
\text { FHI }(n=43)\end{array}$ & $\begin{array}{l}\text { Major } \\
\text { FHI }\end{array}$ & $\begin{array}{l}\text { Minor } \\
\text { FHI }\end{array}$ \\
\hline \multicolumn{4}{|l|}{ Timing of FHI* } \\
\hline $\begin{array}{c}\text { During fetal manipulation prior to } \\
\text { any attempt at cardiac access } \dagger\end{array}$ & $1(2 \%)$ & 1 & 0 \\
\hline $\begin{array}{l}\text { During attempted cardiac access, } \\
\text { before the heart was entered }\end{array}$ & $7(16 \%)$ & 5 & 2 \\
\hline $\begin{array}{l}\text { After introduction of the cannula } \\
\text { into the heart, before balloon } \\
\text { inflation }\end{array}$ & $18(42 \%)$ & 14 & 4 \\
\hline $\begin{array}{l}\text { During or after balloon inflation } \\
\text { while procedural instruments } \\
\text { were still in the heart }\end{array}$ & $4(9 \%)$ & 4 & 0 \\
\hline $\begin{array}{l}\text { After removal of all instruments } \\
\text { from the heart }\end{array}$ & $13(30 \%)$ & 12 & 1 \\
\hline
\end{tabular}

* Listed in temporal order of the procedure.

$\dagger$ Fetus with preexisting hydrops.

developed FHI were younger than those that did not (23.5 \pm 2.3 versus $25.1 \pm 2.4 \mathrm{wk}, p=0.03$ ). There was a large hemopericardium in seven of 31 fetuses that developed major FHI, compared with two of 35 that did not $(p=0.07)$; the developing hemopericardium was typically evident before the onset of FHI. However, aside from ventricular access and gestational age, none of the independent variables analyzed were associated with major FHI or with any FHI.

Among 58 fetuses that underwent attempted balloon aortic valvuloplasty, severe FHI was associated with severe LV distortion during cardiac puncture [OR $=4.4$ (95\% CI: $0.98-$ $19.5), p=0.06]$ and with smaller short-axis LV end-diastolic dimension (0.99 \pm 0.16 versus $1.34 \pm 0.39 \mathrm{~cm}, p=0.008)$.

Fetal resuscitation and management of FHI. Fetal resuscitation was performed in all 31 cases of major FHI. Intramuscular $(n=25)$ and/or intracardiac $(n=23)$ epinephrine was given in 30 cases and intracardiac atropine in seven (in one, the only resuscitation medication was atropine). Eighteen fetuses received both intramuscular and intracardiac epinephrine; the first dose was intramuscular in 11 and intracardiac in seven. Seven fetuses received intramuscular but not intracardiac epinephrine. Among the 31 procedures with major FHI, a median of $2.0 \mathrm{~min}$ (range, $0.3-12.1 \mathrm{~min}$ ) elapsed between the diagnosis of bradycardia and the first dose of resuscitation medication, and a median of two medication doses (range, one to six) was administered. The median duration between the first medication dose and resolution of FHI was $4.2 \mathrm{~min}$ (range, 0.5-30 min). Multiple doses of medication were given in 22 fetuses, and three or more doses were given in 12, most with severe FHI. Although our clinical impression was that FHI responded more rapidly and reliably to intracardiac than intramuscular medication, we did not find quantitative evidence to support this impression: there were no differences in the duration from treatment to resolution of FHI according to the route of medication administration, the first route of administration, or the order of administration routes, and no difference between the durations from first intramuscular and intracardiac medication doses to resolution of FHI.

Outcome of FHI. Ultimately, the heart rate and ventricular function normalized in all fetuses with FHI, with bradycardia
Table 2. Procedural and technical details of prenatal balloon aortic or pulmonary valvuloplasty in 66 fetuses

\begin{tabular}{|c|c|c|}
\hline Variable & $\begin{array}{l}\text { Median (range) or } \\
\text { frequency }(\% \text { of } 66)\end{array}$ & $p^{*}$ \\
\hline \multicolumn{3}{|l|}{ Fetal factors } \\
\hline Gestational age (wk) & $23.5(20-33)$ & 0.03 \\
\hline Hydrops fetalis & $7(11 \%)$ & 0.69 \\
\hline $\begin{array}{c}\text { Fetal anesthesia including } \\
\text { pancuronium } \dagger\end{array}$ & $22(33 \%)$ & 0.85 \\
\hline \multicolumn{3}{|l|}{ Maternal-placental factors } \\
\hline Transplacental fetal puncture & $22(33 \%)$ & 0.79 \\
\hline Laparotomy performed & $23(35 \%)$ & 0.81 \\
\hline Maternal general anesthesia only末 & $19(29 \%)$ & 0.88 \\
\hline Maternal hypotension & $17(26 \%)$ & 0.40 \\
\hline $\begin{array}{l}\text { Maternal therapy with ephedrine or } \\
\text { Neo-Synephrine }\end{array}$ & $54(82 \%)$ & 0.35 \\
\hline $\begin{array}{l}\text { No. of uterine punctures with access } \\
\text { cannula§ }\end{array}$ & $2(1-6)$ & 0.88 \\
\hline \multicolumn{3}{|l|}{ Procedural factors } \\
\hline $\begin{array}{l}\text { No. of ventricular punctures with } \\
\text { access cannula }\end{array}$ & $1(0-6)$ & 0.85 \\
\hline $\begin{array}{l}\text { Ventricular access } \geq 45 \text { degrees off } \\
\text { axis relative to valve }\end{array}$ & $10(15 \%)$ & 0.74 \\
\hline $\begin{array}{l}\text { Ventricular access complicated by } \\
\text { difficult imaging }\end{array}$ & $9(14 \%)$ & 0.15 \\
\hline $\begin{array}{l}\text { Attempted ventricular access with } \\
\text { uncertain cannula or wire } \\
\text { position }\end{array}$ & $18(27 \%)$ & 0.26 \\
\hline \multicolumn{3}{|l|}{$\begin{array}{l}\text { Degree of ventricular distortion } \\
\text { during ventricular puncture }\end{array}$} \\
\hline $\begin{array}{l}\text { Moderate (incomplete but }>50 \% \\
\text { cavity obliteration) }\end{array}$ & $34(52 \%)$ & 0.49 \\
\hline $\begin{array}{l}\text { Severe (complete cavity } \\
\text { obliteration) }\end{array}$ & $10(15 \%)$ & 0.78 \\
\hline $\begin{array}{l}\text { Extensive cannula manipulation/ } \\
\text { repositioning within ventricle }\end{array}$ & $10(15 \%)$ & 0.30 \\
\hline Large hemopericardium & $9(14 \%)$ & 0.07 \\
\hline No. of balloon inflations & $3(0-6)$ & 0.11 \\
\hline Technically successful PCI & $50(76 \%)$ & 0.08 \\
\hline $\begin{array}{l}\text { Total duration of time with cannula in } \\
\text { ventricle (min) }\end{array}$ & $5.5(0.5-31)$ & 0.86 \\
\hline Duration of procedure $(\min ) \dagger$ & $95(34-240)$ & 0.11 \\
\hline
\end{tabular}

Data are presented as frequency (percentage of procedures) or median (range).

* $p$ Values are for association with any (major or minor) FHI.

$\dagger$ Pancuronium instead of vecuronium.

$\$$ Without spinal or epidural anesthesia in addition to or instead of general anesthesia.

$\S$ Does not include uterine punctures with 22-gauge needle used for amniocentesis or medications.

$\dagger$ Duration of procedure measured from initiation until discontinuation of maternal anesthesia.

lasting a median of $6.5 \mathrm{~min}$ (range, 0.5-32 min), including the six fetuses with minor FHI. There was a trend toward longer procedure time in fetuses that developed FHI than in those that did not $(109 \pm 42$ versus $92 \pm 39 \min , p=0.11)$.

In a subset of cases, the technical success of PCI was affected by FHI, which contributed to the decision to halt the procedure in five of 17 technically unsuccessful cases $(p=$ $0.08)$. PCI was unsuccessful in five of 11 fetuses that experienced severe FHI $(p=0.02)$. When FHI occurred during attempted passage of the wire across the valve or during balloon inflation, the procedure was typically continued and resuscitation commenced once the dilation was performed. In 
11 cases, additional attempts at ventricular access were made after resolution of FHI.

Five fetuses died within $1 \mathrm{~d}$ of PCI, four of which had procedural FHI (one minor, one major, two severe) $(p=$ 0.12 ), and two of which underwent PCI for hydrops due to structural heart disease. Two of these fetuses underwent fetopsy. One of these, which died $4 \mathrm{~h}$ after aortic valvuloplasty, was found to have a massive hemopericardium (Fig. 3). No conclusive cause of death was determined for the other.

Procedural complications. Small pericardial fluid collections were common during PCI with both atrial and ventricular access. A large hemopericardium occurred during PCI in nine fetuses, all of which underwent PCI with attempted transventricular access, and seven of which developed major FHI (see above). Drainage of the effusion was attempted in five of these fetuses, and was successful in removing pericardial blood in three, even when portions of the hemopericardium appeared echogenic (Fig. 4). In one case, pericardial drainage resulted in almost immediate improvement of FHI. One fetal death was clearly due to hemopericardium (Fig. 4).

Supraventricular tachycardia occurred in two fetuses, during or soon after PCI. One improved spontaneously; the other was treated successfully with digoxin. Transient atrioventricular dissociation was also recognized in one fetus during resolution of FHI. A chorioamniotic separation developed the
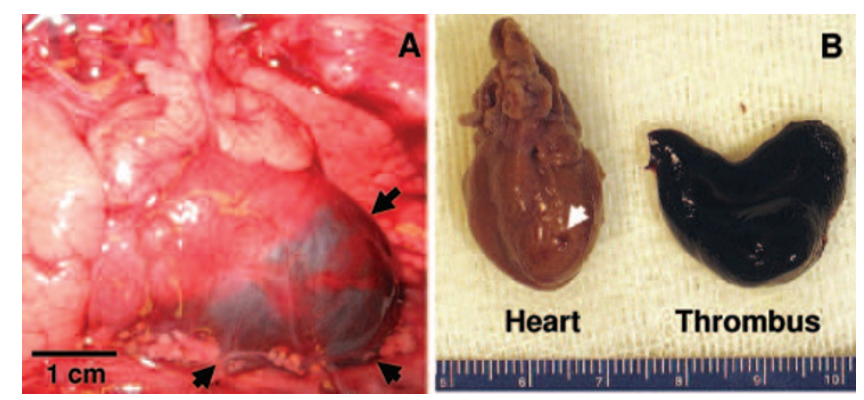

Figure 3. Fetopsy specimen from a fetus that died $4 \mathrm{~h}$ after technically successful fetal aortic valvuloplasty. (A) The fetal mediastinum is exposed, demonstrating a tense pericardium (arrows) with a dark appearance consistent with intrapericardial thrombus. $(B)$ The heart was surrounded anteriorly and apically by a thrombus of similar size. The apical LV puncture site is indicated with the white arrow. Images courtesy of Robert F. Padera, Jr., M.D., Ph.D. Scale bars indicate $1 \mathrm{~cm}$.
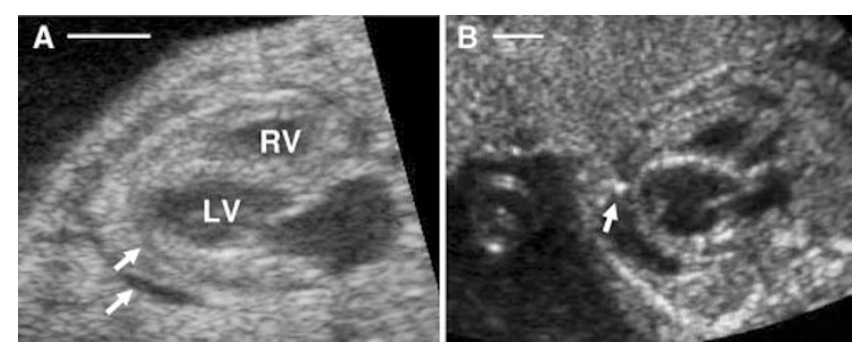

Figure 4. Long-axis echocardiograms demonstrating a partially coagulated hemopericardium after transventricular fetal aortic valvuloplasty $(A)$ and drainage of a hemopericardium $(B)$. (A) The pericardial space has echolucent regions consistent with liquid blood and echogenic areas consistent with thrombus; arrows demarcate the epicardial surface of the LV and the pericardium. $(B)$ The arrow is positioned over the hemopericardium and indicates the tip of the pericardiocentesis needle. day after PCI in one patient who did not have procedural FHI and resolved $1 \mathrm{~d}$ later.

\section{DISCUSSION}

Clinical significance of FHI during PCI. FHI characterized by bradycardia and ventricular dysfunction was common during PCI with ventricular puncture, but rare with transatrial PCI. In most cases, FHI improved after epinephrine, with normalization of heart rate and function within $10 \mathrm{~min}$. However, a subset of patients had prolonged FHI that resolved only after multiple doses of epinephrine. Although FHI improved in all cases, its clinical impact was significant: five procedures were halted without achieving success in part because of FHI, cases with FHI were longer, and FHI occurred in four of five fetuses (two with hydrops) that died within $1 \mathrm{~d}$ of PCI.

Pathophysiology of FHI during PCI. The pathophysiology of PCI-associated FHI is unclear. It is a complex problem that may be influenced by many factors, and we have limited physiologic data from the periprocedure period with which to examine the process. Nevertheless, several important findings of this study may further our understanding of the pathophysiology of PCI-associated FHI.

The association of FHI with attempted ventricular but not atrial access links bradycardia and ventricular dysfunction to transventricular access to or manipulation of the fetal heart. Thus, it is likely that inciting factors for FHI include either direct cardiac stimulation or trauma, which might induce arrhythmias, injure the coronary arteries, or stimulate ventricular mechanoreceptors or one or more autonomic reflexes. Given the variety of conditions during which FHI occurred, maternal-placental, procedural, and/or fetal factors may have contributed as well.

The two most promising hypotheses to explain the cause of FHI during PCI are fetal hypoxia and a direct ventricular stretch response. There is abundant evidence that fetal hypoxia causes bradycardia, primarily through a carotid chemoreceptor reflex (15-17). Accordingly, carotid arterial hypoxia may contribute to PCI-related FHI. Based on the association of FHI with ventricular access, PCI-induced fetal hypoxia would likely result from entering or working within the ventricle. Such mechanisms might include reduced cardiac output due to compression of the inferior vena cava or right heart during cardiac access or manipulation of the cannula, or cardiac tamponade from hemopericardium. In addition to hypoxia, reduced cardiac preload from caval obstruction may affect fetal vasoactive and stress hormones (18), potentially contributing to FHI as well. Although the hypothesis that fetal hypoxia during PCI produces FHI is attractive, we did not find evidence that hypoxia-inducing events increased the risk of FHI.

Another hypothesis for the cause of FHI during transventricular PCI is a mechanically transduced ventricular reflex. Postnatally, stimulation of ventricular stretch receptors with acute distention or preload reduction can produce reflex bradycardia and hypotension due to a combination of vagal efferent activity and withdrawal of sympathetic outflow, the so-called Bezold-Jarisch reflex (19). Little is known about 
ventricular stretch responses in the human fetus. Acute or severe reduction in ventricular preload in late-gestation fetal animal models produces reflex bradycardia by a combination of vagal activation and sympathetic withdrawal, suggesting that a Bezold-Jarisch reflex may be operative in the fetus $(18,20)$. However, in mid-gestation fetal lambs with a normal $\mathrm{LV}$, apical puncture and chronic instrumentation of the LV can be performed without FHI (Abraham M. Rudolph, M.D., personal communication).

PCI-related FHI is likely caused at least in part by a ventricular stretch reflex due to access-related distortion of the abnormal ventricles in fetuses undergoing PCI. Ventricular distortion is most notable on ventricular entry, when the wall of the ventricle is depressed into the cavity (Fig. 2), but may also result from torsion during repositioning of the cannula within the ventricle or distending traction during withdrawal of the dilating balloon from the heart. Severe FHI was associated with severe ventricular distortion during ventricular puncture in our series. Hypoxia due to distortion of the heart during ventricular puncture and consequently reduced ventricular filling and output may also contribute.

In addition, hemopericardium might impair ventricular filling and contribute to a ventricular reflex or tamponade, an important consideration given the association between FHI and a large hemopericardium in our patients and the massive hemopericardium found on fetopsy in one of the fetal deaths.

Coronary arterial or conduction system injury during ventricular puncture might also cause FHI, although the transient and medication-responsive nature of FHI in our cases is inconsistent with coronary laceration. Similarly, although we observed decremental heart block that ultimately resolved in one fetus with major FHI, heart block and arrhythmias were rare during PCI and did not appear to contribute to FHI.

Aside from the direct fetal physiologic perturbations that PCI may induce, maternal-placental factors might also contribute to fetal hypoxia and FHI, from reduction in uterine blood flow due to anesthesia-related maternal hypotension, maternal hypoxemia, or impaired maternal preload due to compression of the inferior vena cava by the gravid uterus during fetal positioning (21-25). Employing the anesthetic methods described, maternal hypotension was uncommon in our experience and was not associated with FHI.

Other factors to consider in the pathophysiology of PCIassociated FHI include the anesthetic agents administered during PCI, as well as the systemic stress response mounted by a fetus undergoing invasive procedures, which manifests with changes in regional vascular resistances and distribution of fetal blood flow, along with tachycardia $(21,26,27)$. Although fentanyl inhibits some of these processes, it may be associated with hemodynamic effects on the fetus in its own right (26). The uniform use of fentanyl in this series precludes assessment of the potential relationship between fetal fentanyl and FHI, whether contributory or protective.

The physiologic background of fetuses undergoing PCI may factor into FHI. Namely, there may be anatomic, circulatory, or other abnormalities in fetuses with complex heart disease that alter the regulation of the fetal circulation or predispose to reflex-mediated FHI. Carotid arterial oxygen saturation in fetuses with evolving HLHS or HRHS is almost certainly lower than in fetuses with a normal circulation, in which streaming of umbilical and systemic venous return facilitates delivery of more highly saturated blood to the myocardium and brain (28). Given that the bradycardic response to hypoxia occurs more rapidly and is prolonged in fetuses with lower baseline carotid oxygen saturation (22), this small alteration in carotid oxygenation may affect the propensity for FHI. Moreover, in fetuses without effective intracardiac streaming of umbilical and systemic venous blood, such as those with evolving HLHS or HRHS, the normal fetal compensatory mechanisms to hypoxia may be impaired (25).

There are other features of evolving HLHS or HRHS that may be important in the pathophysiology of FHI. The LV or $\mathrm{RV}$ is always abnormal, which may have an impact on the ventricular response to stretch. Of note, among fetuses with evolving HLHS in this series, those with severe FHI had significantly smaller LV end-diastolic dimension. Also, cerebral vascular resistance in fetuses with HLHS is typically lower than normal (29), presumably as a compensatory mechanism to optimize cerebral blood flow in the setting of a cerebral circulation supplied retrograde through the ductus arteriosus. This process may be mediated by carotid baroreceptor- or chemoreceptor-dependent mechanisms, and autonomic regulation of cardiac function may be perturbed in such circumstances.

Management of FHI during PCI. Assuming that PCIassociated FHI may be mediated by a combination of increased vagal activity and concomitant sympathetic withdrawal, the optimal therapy for FHI would include both anticholinergic and sympathomimetic agents. To accomplish this, we administer atropine to the fetus at the outset of the procedure and epinephrine after identification of FHI.

Atropine, given with fetal anesthesia, does not prevent all cases of FHI, for which there are several possible explanations: (1) FHI is not mediated entirely by a cholinergic process, (2) the bioavailability of the intramuscular atropine dose is insufficient to block a cholinergically mediated bradycardic response when it typically occurs, 15-60 min after the atropine is given. The ineffectiveness of prophylactic atropine is consistent with the hypothesis that sympathetic withdrawal contributes to PCI-associated FHI, but may also indicate the need for higher dosing.

Although our data do not demonstrate a difference in efficacy between intracardiac and intramuscular epinephrine for acute treatment of FHI, our clinical impression is that intracardiac dosing has a greater and more rapid effect. Decisions about the route of epinephrine administration depend on anticipated efficacy, ease of access, and the possibility that an additional cardiac puncture will exacerbate FHI. Generally, when administering intracardiac medications, we prefer to enter the atrium instead of the ventricle, although ventricular puncture is often more straightforward due to fetal position. Recently, we have administered prophylactic epinephrine through the wire lumen of the balloon catheter after aortic valvuloplasty, with avoidance of FHI in five of six fetuses.

Given the potential hemodynamic importance of hemopericardium during PCI, our current policy is to attempt drainage 
in all fetuses with a large hemopericardium and FHI. If the hemopericardium develops during PCI, the valvuloplasty cannula is used for pericardiocentesis during withdrawal from the heart; otherwise, a separate needle is introduced.

Major FHI was common during PCI with ventricular access, but did not occur with transatrial access only. PCIassociated FHI may be caused by a ventricular reflex or reduced cardiac output from cardiac distortion during ventricular puncture and may be potentiated by fetal hypoxia, predisposing physiologic factors in fetuses with LV or RV outflow obstruction, and/or maternal-placental factors. Although resuscitation was successful in all cases, FHI may be an important contributor to failure of PCI and possibly to adverse fetal outcome. Potential mid- or long-term effects of FHI have not been defined.

Acknowledgments. The authors acknowledge Abraham M. Rudolph, M.D., and Julien I.E. Hoffman, M.D., for their generous and insightful consultation during the planning of this manuscript.

\section{REFERENCES}

1. Vlahos AP, Lock JE, McElhinney DB, van der Velde ME 2004 Hypoplastic left heart syndrome with intact or highly restrictive atrial septum: outcome after neonatal transcatheter atrial septostomy. Circulation 109:2326-2330

2. Rychik J, Rome JJ, Collins MH, DeCampli WM, Spray TL 1999 The hypoplastic left heart syndrome with intact atrial septum: atrial morphology, pulmonary vascular histopathology and outcome. J Am Coll Cardiol 34:554-560

3. Fishman NH, Hof RB, Rudolph AM, Heymann MA 1978 Models of congenital heart disease in fetal lambs. Circulation 58:354-364

4. Hogers B, DeRuiter MC, Gittenberger-de Groot AC, Poelmann RE 1997 Unilateral vitelline vein ligation alters intracardiac blood flow patterns and morphogenesis in the chick embryo. Circ Res 80:473-481

5. Sedmera D, Hu N, Weiss KM, Keller BB, Denslow S, Thompson RP 2002 Cellular changes in experimental left heart hypoplasia. Anat Rec 267:137-145

6. Hornberger LK, Sanders SP, Rein AJ, Spevak PJ, Parness IA, Colan SD 1995 Left heart obstructive lesions and left ventricular growth in the midtrimester fetus: a longitudinal study. Circulation 92:1531-1538

7. Mäkikallio K, McElhinney DB, Levine JC, Marx GR, Colan SD, Marshall AC, Lock JE, Marcus EN, Tworetzky W 2006 Fetal aortic valve stenosis and the evolution of hypoplastic left heart syndrome: patient selection for fetal intervention. Circulation 113:1401-1405

8. Tworetzky W, Wilkins-Haug L, Jennings RW, van der Velde ME, Marshall AC, Marx GR, Colan SD, Benson CB, Lock JE, Perry SB 2004 Balloon dilation of severe aortic stenosis in the fetus: potential for prevention of hypoplastic left heart syndrome: candidate selection, technique, and results of successful intervention. Circulation 110:2125-2131

9. Marshall AC, van der Velde ME, Tworetzky W, Gomez CA, Wilkins-Haug L, Benson CB, Jennings RW, Lock JE 2004 Creation of an atrial septal defect in utero for fetuses with hypoplastic left heart syndrome and intact or highly restrictive atrial septum. Circulation 110:253-258

10. Marshall AC, Tworetzky W, Bergersen L, McElhinney DB, Benson CB, Jennings RW, Wilkins-Haug LE, Marx GR, Lock JE 2005 Aortic valvuloplasty in the fetus: technical characteristics of successful balloon dilation. J Pediatr 147:535-539

11. Graf JL, Paek BW, Albanese CT, Farrell JA, Kitterman JA, Jennings RW, Harrison MR 2000 Successful resuscitation during fetal surgery. J Pediatr Surg 35:1388-1389

12. Elliott JP, Foley MR, Finberg HJ 1994 In utero fetal cardiac resuscitation: a case report. Fetal Diagn Ther 9:226-228

13. Brumfield SS, Fausett MB, Fries MH 2005 Intrauterine fetal resuscitation following complications of closed fetal surgery. Fetal Diagn Ther 20:272-274

14. Wilkins-Haug LE, Tworetzky W, Benson CB, Marshall AC, Jennings RW, Lock JE 2006 Factors affecting technical success of fetal aortic valve dilation. Ultrasound Obstet Gynecol 28:47-52

15. Bartelds B, van Bel F, Teitel DF, Rudolph AM 1993 Carotid, not aortic, chemoreceptors mediate the fetal cardiovascular response to acute hypoxemia in lambs. Pediatr Res 34:51-55

16. Boekkooi PF, Baan J, Teitel D, Rudolph AM 1992 Chemoreceptor responsiveness in fetal sheep. Am J Physiol 263:H162-H167

17. Baan J, Boekkooi PF, Teitel DF, Rudolph AM 1993 Heart rate fall during acute hypoxemia: a measure of chemoreceptor response in fetal sheep. J Dev Physiol 19:105-111

18. Wood CE, Keil LC, Rudolph AM 1982 Hormonal and hemodynamic responses to vena caval obstruction in fetal sheep. Am J Physiol 243:E278-E286

19. Hainsworth R 1995 Cardiovascular reflexes from ventricular and coronary receptors Adv Exp Med Biol 381:157-174

20. Nuyt AM, Segar JL, Holley AT, Robillard JE 2001 Autonomic adjustments to severe hypotension in fetal and neonatal sheep. Pediatr Res 49:56-62

21. Rudolph AM, Itskovitz J, Iwamoto H, Reuss ML, Heymann MA 1981 Fetal cardiovascular responses to stress. Semin Perinatol 5:109-121

22. Itskovitz J, Goetzman BW, Rudolph AM 1982 The mechanism of late deceleration of the heart rate and its relationship to oxygenation in normoxemic and chronically hypoxemic fetal lambs. Am J Obstet Gynecol 142:66-73

23. Hill JB, Alexander JM, Sharma SK, McIntire DD, Leveno KJ 2003 A comparison of the effects of epidural and meperidine analgesia during labor on fetal heart rate. Obstet Gynecol 102:333-337

24. Cleary-Goldman J, Negron M, Scott J, Downing RA, Camann W, Simpson L, Flood P 2005 Prophylactic ephedrine and combined spinal epidural: maternal blood pressure and fetal heart rate patterns. Obstet Gynecol 106:466-472

25. Reuss ML, Rudolph AM 1980 Distribution and recirculation of umbilical and systemic venous blood flow in fetal lambs during hypoxia. J Dev Physiol 2:71-84

26. Smith RP, Miller SL, Igosheva N, Peebles DM, Glover V, Jenkin G, Hanson MA, Fisk NM 2004 Cardiovascular and endocrine responses to cutaneous electrical stimulation after fentanyl in the ovine fetus. Am J Obstet Gynecol 190:836-842

27. Fisk NM, Gitau R, Teixeira JM, Giannakoulopoulos X, Cameron AD, Glover VA 2001 Effect of direct fetal opioid analgesia on fetal hormonal and hemodynamic stress response to intrauterine needling. Anesthesiology 95:828-835

28. Edelstone DI, Rudolph AM 1979 Preferential streaming of ductus venosus blood to the brain and heart in fetal lambs. Am J Physiol 237:H724-H729

29. Kaltman JR, Di H, Tian Z, Rychik J 2005 Impact of congenital heart disease on cerebrovascular blood flow dynamics in the fetus. Ultrasound Obstet Gynecol 25:32-36 